\title{
Steroids Administration at Term in Egypt: Does it become a Routine Practice?
}

\author{
Ayman S Dawood ${ }^{1 *}$ and Hesham A Salem ${ }^{2}$ \\ ${ }^{1}$ Lecturer of Obstetrics and Gynecology, Tanta University, Egypt \\ ${ }^{2}$ Professor of Obstetrics and Gynecology, Tanta University, Egypt
}

*Corresponding author: Ayman Shehata Dawood, Department of Obstetrics and Gynecology, Tanta University, Tanta, 31111, Egypt.

Received Date: April 30, 2019

Published Date: May 03, 2019

\section{Abstract \\ Background: Antenatal steroids become a routine daily practice before elective Cesarean deliveries in Egypt. These drugs were recommended only from 24 weeks to 34 weeks of gestation to minimize respiratory morbidities in newborn. Steroids are not without side effects or complications for both the baby and the mother.}

Objective: To evaluate the evidence regarding the use of antenatal steroids at term prior to scheduled cesarean delivery.

Materials and Methods: Reviewing published data in recent ten years since January 2009 till 31, December 2017.

Results: Antenatal steroids were recommended only from 24 weeks to 34 weeks with extension up to 37 weeks of gestation not later to minimize respiratory morbidities in newborn.

Conclusion: Steroids are not without side effects or complications for both the baby and the mother. These drugs should be limited to high risk patients with imminent preterm birth and discouraged before term deliveries till evidence approve its long-term safety.

Keywords: Antenatal steroids; Scheduled; Cesarean delivery; Neonatal; Maternal outcomes

\section{Introduction}

Antenatal steroids were mainly given in high risk situations with eminent preterm birth as multiple gestations, cervical incompetence, polyhydramions and patients with history of previous preterm birth. Corticosteroids are of great benefit for normal development and enhancement of lung maturity. Evidence supports the use of steroids in those patients with strong limitation to single course and discouraging multiple weekly courses. Many authors advocate the use of steroids at term before scheduled cesarean delivery, but other institutions disagree with the results and conclusions of these studies [1,2].

\section{Discussion}

Nowadays, many studies emerged with evidence supporting the use of such drugs before term cesarean delivery $\leq 39$ weeks. This practice became a routine daily practice even in gestations beyond 39 weeks. Many researchers advised the use of steroids before term elective cesarean section to reduce respiratory and composite morbidities [3-5].
On the other hand, many studies found that exposure of the fetus at term to corticosteroids either by betamethasone or dexamethasone can profoundly affect the development of the neuroendocrine system at term than at any other time in pregnancy duration. These drugs had life-long effects on endocrine system, emotions, affection and cognitive functions. These side effects of corticosteroids are still under continuous investigation and evidence till now didn't reach to a final conclusion regarding this issue [6,7].

Do exogenous synthetic steroids affect endogenous corticosteroids surge near term? Do they affect the mechanism and initiation of parturition mechanism? Do they affect brain and other organs if they were given prior to delivery? Evidence still had no clear answers to these questions. Debates are still present whether to revise the use of steroids before term cesarean or not $[6,7]$. Nabhan A et al [8], in their study found that prophylactic antenatal corticosteroid for elective cesarean delivery between 34 and 37 
weeks is not effective in improving neonatal outcomes [8]. De Vivo et al, found that wound complications were more in patients who received antenatal steroids before Cesarean section [9].

Davis et al, examined 54 children, at early school age (6-10 years), where they were exposed to a single course of betamethasone in-utero at 29.3 weeks, and delivered at term, and compared them to matched controls. There were alarming findings in children exposed to corticosteroids. They found that great differences in cortical thickness associated with significant thinning of the cortex, which were led to development of affective disorders and hypothalamic-pituitary axis dysregulation [6]. Moreover, antenatal steroids are linked to neonatal hypoglycemia as stated by the American Academy of Pediatrics [10].

The Society for Maternal-Fetal Medicine (SMFM) advised the use of a single course of corticosteroids in late preterm only in cases with imminent delivery [11]. The American College of Obstetricians and Gynecologists expanded the use of antenatal steroids to include gestations from 23 to 37 weeks [12]. Today' shift of these drugs to term pregnancies $>37$ weeks is not recommended by previously mentioned organizations. On the other hand, obstetricians should avoid elective deliveries before 39 weeks to reduce the morbidity associated with these deliveries $[11,12]$.

Finally, balanced use of these drugs should be settled, and routine use of steroids should be discouraged till evidence of their long-term safety is clear.

\section{Limitation of Study}

The limited number of studies assessing delayed complications of corticosteroids given during pregnancy but nearly no studies were found to assess the same outcomes following their administration at term.

\section{Conclusion}

Routine use of steroids before scheduled deliveries prior to 39 weeks should be discouraged in low risk patients. These drugs are not safe enough to be abused in such manner. These drugs have both short term and long-term complications. The risk for irreversible changes in the brain and the hypo-pituitary axis, should be considered when prophylactic steroids are prescribed.

\section{Acknowledgment}

None.

\section{Conflict of Interest}

No conflict of interest.

\section{References}

1. Saccone G, Berghella V (2016) Antenatal corticosteroids for maturity of term or near-term fetuses: systematic review and meta-analysis of randomized controlled trials. BMJ 355: iS044.

2. Kirshenbaum M, Mazaki-Tovi S, Amikam U, Mazkereth R, Sivan E, et al (2016) Does antenatal steroids treatment prior to elective cesarean section at 34-37 weeks of gestation reduce neonatal morbidity? Evidence from a case control study. Arch Gynecol Obstet 297(1): 101107.

3. Stutchfield PR, Whitaker R, Gliddon AE, Hobson L, Kotecha S, et al. (2013) Behavioural, educational and respiratory outcomes of antenatal betamethasone for term caesarean sect (ASTECS trial). Arch Dis Child Fetal Neonatal Ed 98(3): F195-F200.

4. Petour Gazitúa F, Pérez Velásquez J (2015) Do antenatal corticosteroids in term elective cesarean sections reduce neonatal respiratory morbidity? Medwave 15(9): e6280.

5. Ahmed MR, Sayed Ahmed WA, Mohammed TY (2015) Antenatal steroids at 37 weeks, does it reduce neonatal respiratory morbidity? A randomized trial. J Matern Fetal Neonatal Med 28(12): 1486-1490.

6. Davis EP, Sandman CA, Buss C, Wing DA, Head K (2013) Fetal glucocorticoid exposure is associated with preadolescent brain development. Biol Psychiatry 74(9): 647-655.

7. Chang YP (2014) Evidence for adverse effect of perinatal glucocorticoid use on the developing brain. Korean J Pediatr 57(3): 101-109.

8. Nabhan A, Al-Helaly A, Ramadan A (2014) Prophylactic antenatal corticosteroid before elective cesarean delivery at or near term to improve perinatal outcome. Med J Cairo Univ 82(1): 25-28.

9. De Vivo A, Mancuso A, Giacobbe A, Priolo AM, De Dominici R, et al. (2010) Wound length and corticosteroid administration as risk factors for surgical-site complications following cesarean section. Acta Obstet Gynecol Scand 89(3): 355-359.

10. Pettit KE, Tran SH, Lee E, Caughey AB (2014) The association of antenatal corticosteroids with neonatal hypoglycemia and hyperbilirubinemia. J Matern Fetal Neonatal Med 27(7): 683-686.

11. Gyamfi-Bannerman C, Thom EA, Blackwell SC, Tita AT, Reddy UM, et al. (2016) Antenatal betamethasone for women at risk for late preterm delivery. The New England Journal of Medicine 374: 1311-1320.

12. (2016) ACOG Committee on practice bulletins-obstetrics. ACOG practice bulletin no. 150: management of preterm labor. Obstet Gynecol 127: e29. 